Research Article

\title{
CYTOGENETIC EFFECTS OF GAMMA RAYS ON INDICA RICE RADHA-4
}

\author{
S. Basi, L. P. Subedi, G. B. KC and N. R. Adhikari \\ Institute of Agriculture and Animal Sciences, Rampur, Nepal \\ Email: sabinbasi@hotmail.com
}

\begin{abstract}
The present study was conducted to understand the effects of different doses of radiations by gamma rays of $\mathrm{Co}^{60}$ on cytogenetics of indica rice, Radha-4 at the Central Lab, Institute of Agriculture and Animal Science, Rampur, Nepal. The immature PMC of M1 generation plants were analyzed performing the usual smearing and squashing technique. Radiation had a significant effect causing different types of cytogenetic aberrations, such as univalent and multivalent association of chromosomes, chromatin-bridges, laggards, fragments, stickiness, and multinucleated cells. An increasing number of aberrant cells with increasing dose of radiation was identified. The greatest share of aberration was identified due to multivalent association as a result of translocation followed by bridges and laggards, and the least effect for the stickiness of the chromosomes. Finally, $35 \mathrm{KR}$ doses of gamma rays was the most potent dose inducing cytogenetic aberrations in meiotic pollen mother cell of rice compared to other dose spectrum.
\end{abstract}

Key words: Radiation, gamma ray, cytogenetics, chromosomes, aberrations

\section{INTRODUCTION}

Rice farming in Nepal is the foremost industry that contributes about $24 \%$ of the total gross agricultural products (Pokhrel, 1997). Even though the rice is the dominating crop in the national economy, its productivity is far less than $2.5 \mathrm{mt} / \mathrm{ha}$ (Upadhyaya, 1995). There are many production constraints causing low productivity. Among many such hindrances, unavailability of suitable cultivars is the one. Improved cultivars have to be developed, which could improve the production and productivity even under low input conditions. Thus, it is imperative to lay a research on the improvement of genetic architecture of the current rice plant aiming for improvement of its quality and quantity related traits.

Mutation breeding, for its well-known reputation in improving the genetic architecture of the crop plants, may be used as a supplementary or complementary aid in imparting desirable characters in rice plants. There are number of instances when mutation breeding is applied in conferring quick and specific mutational improvements to varieties and advanced breeding lines, induction of polygenic mutations without significantly affecting their performance and shortening the time required for such specific improvement. It has often been used in creating a character, which is not found even in the natural population. Furthermore, its contribution on breaking tight linkages, producing translocations for gene transfer cannot be overlooked (Sears, 1956).

Mutation breeding has been a good aid in imparting better polygenic traits in rice plants. There are several instances when the quality, quantity and stress related traits have been improved following induced mutagenesis (Siddiq, 1985). Inductions of dwarfness, earliness, disease and pest resistance etc. are few of such examples. Further, induced mutation has been applied for inducing genetic variation in rice (Oka et al., 1958).

However, inclusion of mutagenesis in the rice breeding program always necessitates the study of effect and extent of meiotic abnormality. Meiotic study is inevitable to generalize the background of the mutants. This information is essential for a conceptual approach and design of a breeding program and to introduce the induced variation from and to the mutants and to the subsequent lines. Hence, once the useful mutants are identified, its proper utilization in the breeding program can only be achieved when its whole cytogenetic status is available. Further, for the proper exploitation of translocation or inversion stocks, in the breeding or genetic studies, it is inevitable to have a full picture of cytogenetics of the plants. Finally, in mutation studies cytogenetic analysis with respect to either mitotic or meiotic behavior is considered to be one of the most dependable indices to estimate the potency of a mutagen on the one hand and mutagen-response of a genotype on the other. 
Considering the above-mentioned facts, for infinite scope and popularity among workers working in the field of genetics and breeding of crop plants, it is imperative to lay a research in mutation breeding activities for improving yield and quality related studies of rice in Nepal too. The country still has a great opportunity to exploit this unexplored innovative approach of plant breeding. But before venturing into breeding strategy it is sensible to study the radiation effects on cytogenetics. Thus the present study was undertaken to determine the cytogenetic changes accompanying different doses of radiation with gamma ray of $\mathrm{Co}^{60}$ on one of the popular main season rice, Radha 4 of Nepal.

\section{MATERIALS AND METHODS}

A strain of rice, Radha-4 was chosen for this study. Dry seeds, spread in a multi layer in petri dishes, were subjected to the exposure of 20,25, 30 and $35 \mathrm{KR}$ of gamma ray, employing a Theraron Elite $100, \mathrm{Co}^{60}$ source medical gamma ray unit at the B.P. Koirala Memorial Cancer Hospital, Yagyapuri, Chitwan. Treated seeds including the control were planted in Completely Randomized Block Design maintaining single seed per hill, at the Institute of Agriculture and Animal Science, in the spring of 2004.

Spikelets of suitable stages from sampled M1 plants were fixed in Carnoys' II fluid (Glacial Acetic Acid, Chloroform, and 95\% ethanol in the proportion of 1:3:6 respectively) to which traces of ferric chloride were added as mordant (Khan, 1975). The material was collected between 9-10 A.M., when the warmth of sunlight was initiating. The material after fixing for 24 hours, were then transferred to $70 \%$ alcohol and stored in refrigerator until further use. The suitable stage was identified to be as early before booting, when the diameter of boot enclosed sheath is less than half of the just emerging boot of that size. The anthers were squashed in $1 \%$ acetocarmine to which traces of ferric chloride were added (Evans and Reed, 1981).

Data were recorded based on the analysis of 10 randomly selected immature spikelets. After screening a large number of dividing cells, data concerning the meiotic behavior were included only from those PMC that yielded well spread and distinct configuration. Microscopic photographs were taken from the temporary slides with the aid of microscopic camera on a field of 100X oil immersion objective and 10X eyepiece of Olympus microscope.

\section{RESULTS}

\section{Chromosomal association}

Reciprocal translocation as expressed by the multivalent association of chromosomes was observed following radiation. Increasing trend of multivalent association was observed with the increasing dose of radiation. It was observed to have the highest score at $35 \mathrm{KR}(17.94 \%)$ followed by $30 \mathrm{KR}(13.18 \%)$ while the least was observed at $25 \mathrm{KR}(1.14 \%)$ (Table 1).

Table.1. Chromosome association in the cell in response to varying doses of gamma rays

\begin{tabular}{|c|c|c|c|c|c|c|c|c|c|}
\hline \multirow{2}{*}{$\begin{array}{l}\text { Dose } \\
(\mathrm{KR})\end{array}$} & \multirow{2}{*}{$\begin{array}{c}\text { No. of } \\
\text { Plants } \\
\text { analyzed }\end{array}$} & \multirow{2}{*}{$\begin{array}{l}\text { No. of } \\
\text { PMCs } \\
\text { scored }\end{array}$} & \multicolumn{6}{|c|}{ Chromosome association mean (Range) } & \multirow{2}{*}{$\begin{array}{c}\text { Multivalent } \\
\text { cell } \%\end{array}$} \\
\hline & & & I & II & III & IV & VI & XII & \\
\hline \multirow[t]{2}{*}{ Control } & 8 & 270 & $0.09 \pm 0.056$ & $11.96 \pm 0.029$ & & & & & \\
\hline & & & $(0-2)$ & $(11-12)$ & - & - & - & - & 0 \\
\hline \multirow[t]{2}{*}{$20 \mathrm{KR}$} & 8 & 317 & $0.31 \pm 0.097$ & $11.81 \pm 0.06$ & - & $0.02 \pm 0.019$ & & & \\
\hline & & & $(0-2)$ & $(10-12)$ & - & $(0-1)$ & - & - & 1.89 \\
\hline \multirow[t]{2}{*}{$25 \mathrm{KR}$} & 12 & 350 & $0.323 \pm 0.077$ & $11.73 \pm 0.065$ & $0.03 \pm 0.022$ & $0.03 \pm 0.02$ & & & \\
\hline & & & $(0-4)$ & $(8-12)$ & $(0-1)$ & $(0-1)$ & - & - & 1.14 \\
\hline \multirow[t]{2}{*}{$30 \mathrm{KR}$} & 12 & 311 & $0.39 \pm 0.144$ & $11.18 \pm 0.258$ & $0.13 \pm 0.067$ & $0.13 \pm 0.067$ & & & \\
\hline & & & $(0-10)$ & $(7-12)$ & $(0-1)$ & $(0-2)$ & - & - & 13.18 \\
\hline \multirow[t]{2}{*}{$35 \mathrm{KR}$} & 8 & 273 & $0.65 \pm 0.156$ & $10.76 \pm 0.267$ & $0.04 \pm 0.043$ & $0.28 \pm 0.101$ & $0.04 \pm 0.043$ & $0.02 \pm 0.02$ & \\
\hline & & & $(0-3)$ & $(5-12)$ & $(0-1)$ & $(0-2)$ & $(0-1)$ & $(0-1)$ & 17.94 \\
\hline
\end{tabular}


Quadrivalent as an association was observed to be the highest (Table 2) in overall count. And the greatest spectrum of association was observed at $35 \mathrm{KR}$; it included trivalent (0.04), tetravalent (0.28), hexavalent association (0.04) and dodecavalent (0.02) association (Table 1).

Table 2. Nuclear anomalies in PMC of $\mathbf{M}_{1}$ plants expressed in terms of \% abnormal cells at that stage in response to varying doses of gamma rays

\begin{tabular}{|c|c|c|c|c|c|c|c|c|}
\hline \multirow[t]{2}{*}{ Dose (KR) } & \multicolumn{3}{|c|}{ Metaphase I } & \multicolumn{4}{|c|}{ Anaphase I } & \multirow{2}{*}{$\begin{array}{l}\text { Telophase I } \\
\text { and Interphase } \\
\text { Multinucleate } \\
\text { cells }\end{array}$} \\
\hline & Laggard & Stickiness & Fragments & Laggard & Stickiness & Fragments & Bridge & \\
\hline Control & - & - & - & - & - & - & - & - \\
\hline $20 \mathrm{KR}$ & - & & & - & - & - & 1.538 & - \\
\hline $25 \mathrm{KR}$ & 3.007 & - & 1.503 & 1.493 & - & - & 4.479 & 1.28 \\
\hline $30 \mathrm{KR}$ & 3.94 & 0.79 & 0.79 & 3.7 & 1.235 & 4.938 & 4.938 & 2.94 \\
\hline $35 \mathrm{KR}$ & 4.67 & 1.34 & 1.34 & 1.724 & 1.724 & 3.448 & 10.345 & 4.16 \\
\hline
\end{tabular}

Analysis of pollen mother cells at interphase, diplotene, diakinesis, metaphase I and anaphase I showed the occurrence of various types of chromosomal aberration such as reciprocal translocation, chromatin bridge, laggards, sticky chromosomes, fragments and other nuclear abnormalities such as micro/ multinucleated cells. But their frequency was very low and asymmetrical; not only in the treatments as a whole, but also within the single ear of the M1 plants. Highly significant effect $(\mathrm{p}<0.01)$ of radiation was observed with all the treatment as compared to control (Table 3). Increasing trend of aberrant cell was observed with the increasing dose of radiation. The highest effect was observed at $35 \mathrm{KR}(16.51 \%)$ (Table 3).

Table 3. Percentage of abnormalities occurring in the meiotic stages of PMC of $\mathbf{M}_{1}$ plants due to irradiation by varying doses of gamma rays

\begin{tabular}{|c|c|c|c|c|c|c|c|c|c|c|c|c|}
\hline \multirow{3}{*}{$\begin{array}{l}\text { Dose } \\
(\mathrm{KR})\end{array}$} & \multicolumn{4}{|c|}{ No. of cells observed } & \multicolumn{6}{|c|}{ Cells with disturbances } & \multirow{3}{*}{$\begin{array}{l}\text { Cells with } \\
\text { disturb- } \\
\text { ances } \%\end{array}$} & \multirow{3}{*}{$\begin{array}{c}\mathrm{Z} \text {-value } \\
\text { compared } \\
\text { with control }\end{array}$} \\
\hline & $\begin{array}{l}\text { Telophase } \\
\text { I and }\end{array}$ & $\begin{array}{c}\text { Diplotene } \\
- \\
\text { Metaphase }\end{array}$ & Anaphase & $\begin{array}{l}\text { Total } \\
\text { cells }\end{array}$ & \multicolumn{2}{|c|}{$\begin{array}{l}\text { Telophase I and } \\
\text { Interphase }\end{array}$} & \multicolumn{2}{|c|}{$\begin{array}{c}\text { Diplotene - } \\
\text { Metaphase I }{ }^{\circledR}\end{array}$} & \multicolumn{2}{|c|}{ Anaphase I ${ }^{\#}$} & & \\
\hline & & & & & No. & $\%$ & No. & $\%$ & No. & $\%$ & & \\
\hline Control & 48 & 270 & 50 & 368 & - & 0 & - & 0 & - & 0 & - & - \\
\hline $20 \mathrm{KR}$ & 98 & 317 & 65 & 480 & - & 0 & 6 & 1.9 & 1 & 1.53 & 1.46 & $2.33 * *$ \\
\hline $25 \mathrm{KR}$ & 78 & 350 & 67 & 495 & 1 & 1.29 & 10 & 2.86 & 4 & 5.97 & 2.83 & $3.25^{* *}$ \\
\hline $30 \mathrm{KR}$ & 68 & 312 & 81 & 461 & 2 & 2.94 & 48 & 15.39 & 8 & 9.88 & 12.58 & $7.06^{* *}$ \\
\hline $35 \mathrm{KR}$ & 48 & 318 & 58 & 424 & 2 & 4.17 & 60 & 18.87 & 8 & 13.8 & 16.51 & $8.16^{* *}$ \\
\hline
\end{tabular}

**-Significant at 0.01 level of significance. @ - Includes cells having multivalent chromosomes, laggards, fragments and sticky chromosomes. \# Includes cells having bridge, laggards, stickiness and fragments.

\section{Nuclear anomalies in diakinesis-metaphase I}

At this stage, multivalent chromosomes had the highest share followed by laggards and very less frequent stickiness and fragments of chromosomes. The greatest score of $(18.87 \%)$ aberrant cell was observed at 35 KR; while the least was observed at $20 \mathrm{KR}(1.90 \%)$ (Table 3).

Varying range of univalent was observed both with the control and the irradiated PMC. But the mean count on univalent chromosome represented the increasing trend with the increasing dose of radiation. The highest count on average univalents/cell was scored at $35 \mathrm{KR}(0.65)$ and the least with the control (0.09). Increasing univalent chromosomes with increasing dose of radiation were noted. Similarly, the highest number of 10 univalents was observed at 25 and $30 \mathrm{KR}$ (Plate 1, Figure 13)

\section{Laggards, fragments and sticky chromosomes}

Laggards, for being unable to orient at the metaphase plate were observed during metaphase I following the radiation treatment (Plate 2, Figures 5, 6,7). The highest score for laggards, expressed in terms of percentage of metaphase cells having laggards were observed at the radiation dose of $35 \mathrm{KR}(4.67 \%)$. While no laggards were observed at the control and $20 \mathrm{KR}$ treated cells. Occurrence of cells having laggard chromosome had the increasing trend with the increasing dose of radiation (Table 2). 

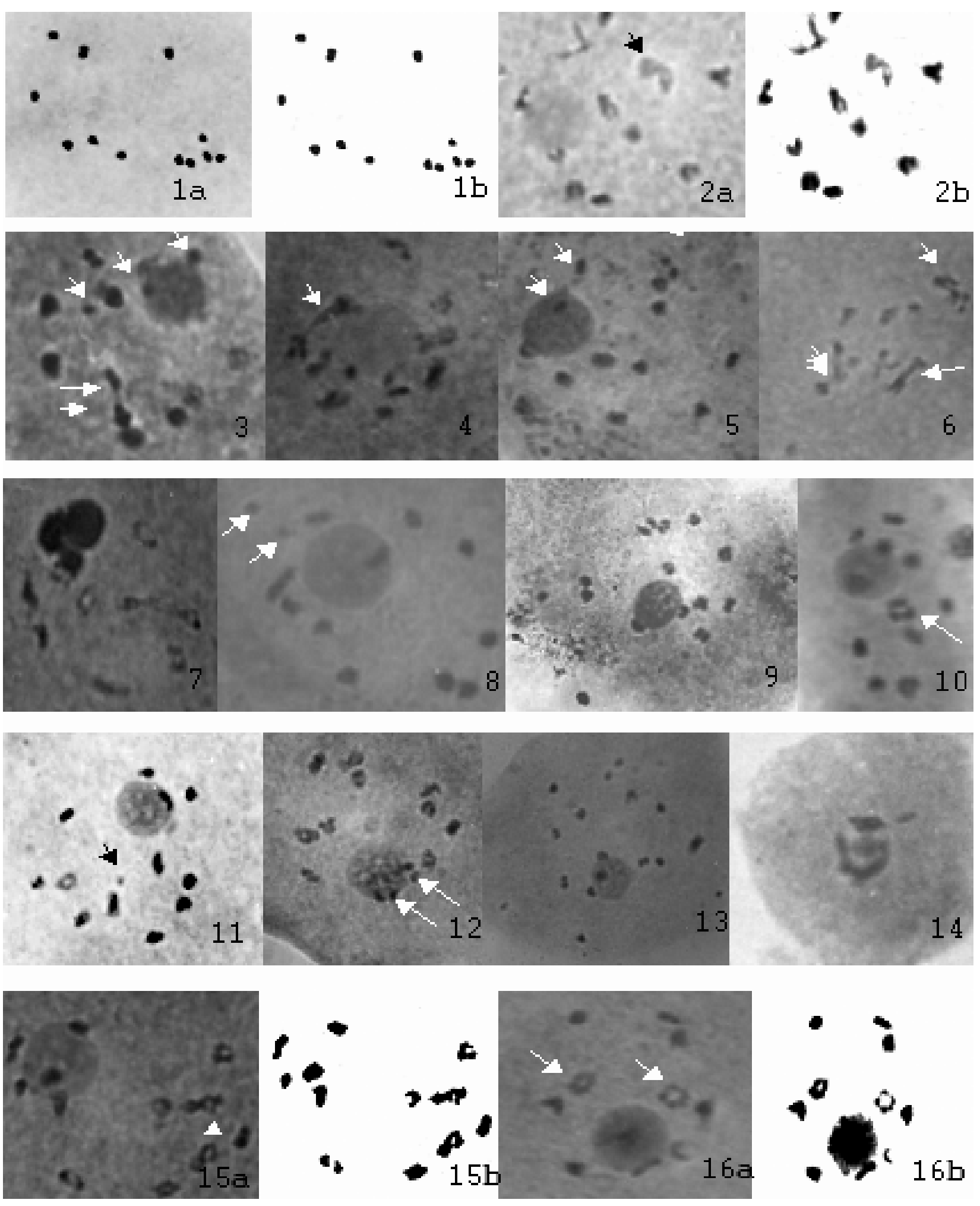

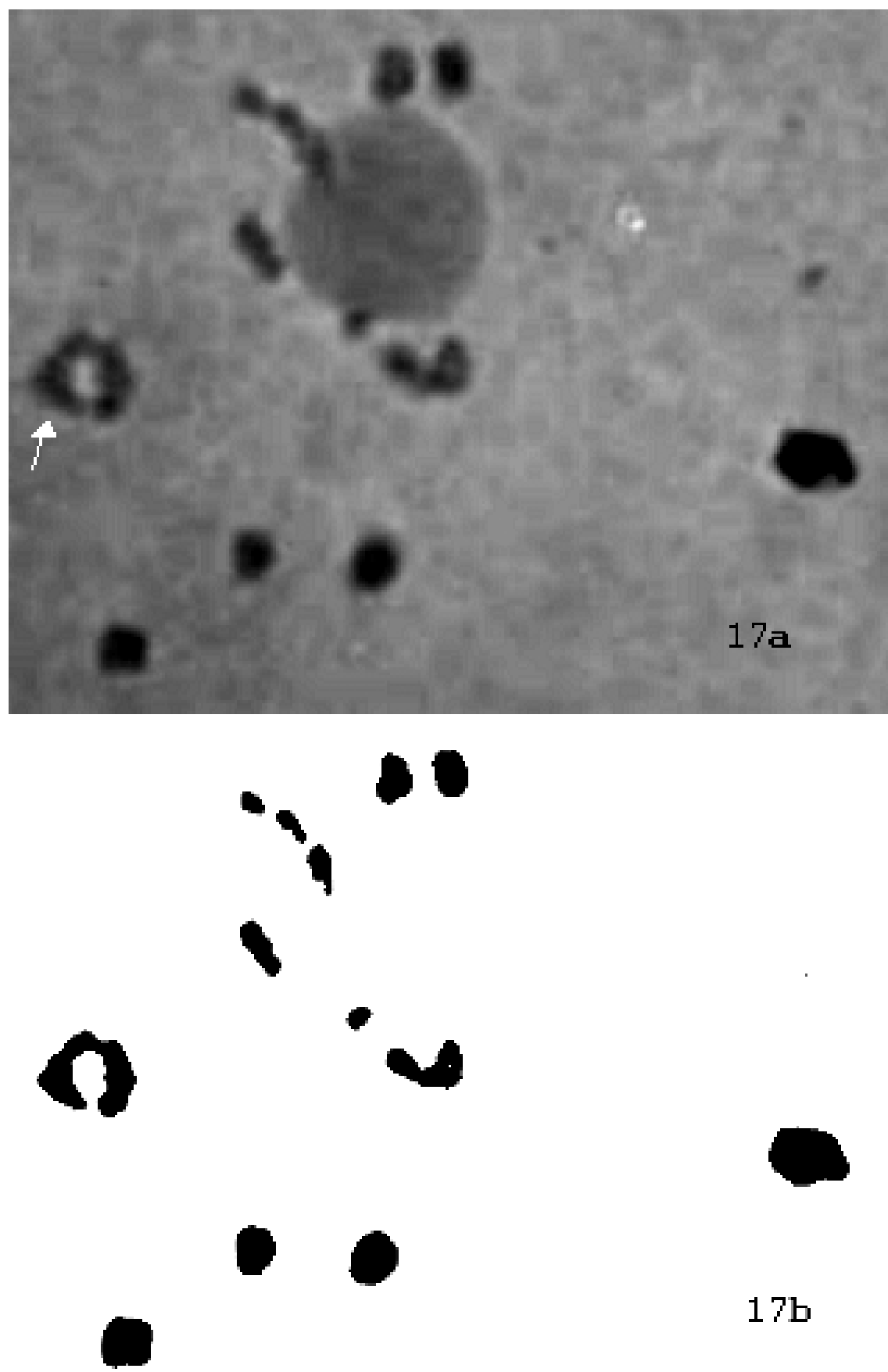

Plate 1. Representative photomicrograph of radiation induced cytogenetic aberration at diplotene and diakinesis. Figure 1.a,b Normal late diakinetic cell with 12 II (0 KR). Figure 2a,b. 11II+1IV (arrowed) 20 (KR). Figure 3. 8II+ 1IV (single arrowed)+4 I (double arrowed), the quadrivalent is attached only by a thin chromatin thread (35 KR). Figure $4.10 \mathrm{II}+1 \mathrm{IV}$ (arrowed) (35KR). Figure 5.10 II + 4 I (arrowed) (30 KR). Figure 6. $5 \mathrm{II}+2 \mathrm{IV}$ (single arrowed) + 1VI (double arrowed) $(35 \mathrm{KR})$. Figure 7. Multiple nucleoli with indistinct chromosomes(35 KR). Figure 8. 11 II + 2 I (arrowed) (35 KR). Figure 9. 10II+ 4 II (30 KR). Figure 10. 10 II+ 1IV (ring form) (arrowed) + extra nuclear body(25 KR). Figure 11. $12 \mathrm{II}+1$ fragment (arrowed) (35 KR). Figure 12. $10 \mathrm{II}+4 \mathrm{I}(25 \mathrm{KR})$. Figure 13. $7 \mathrm{II}+10 \mathrm{I}$ (30 KR). Figure 14. Sticky mass of chromosome (30KR). Figure 15a,b. Late normal 12 II but with break in one chromosome (arrowed). Figure 16 a,b. 9 II + 2 IV (ring form, arrowed) (25 KR). Figure 17a,b. 8 II +1I +1III+1 IV (ring form) $(25 \mathrm{KR})$.

(Figure $\mathrm{b}$ is the retouched micrograph of respective figure a by adjusting the gamma value) 

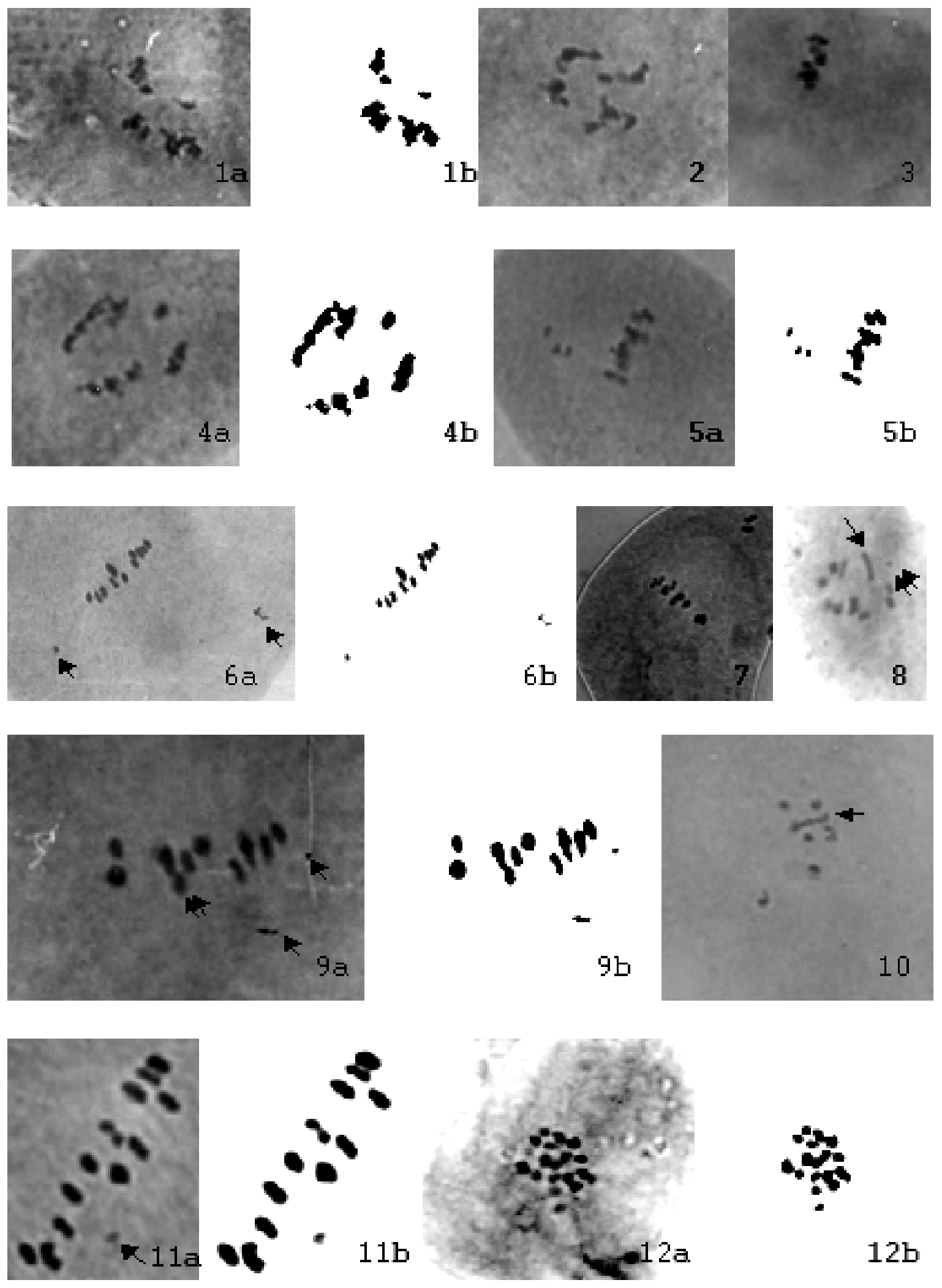

$12 \mathrm{~b}$ 

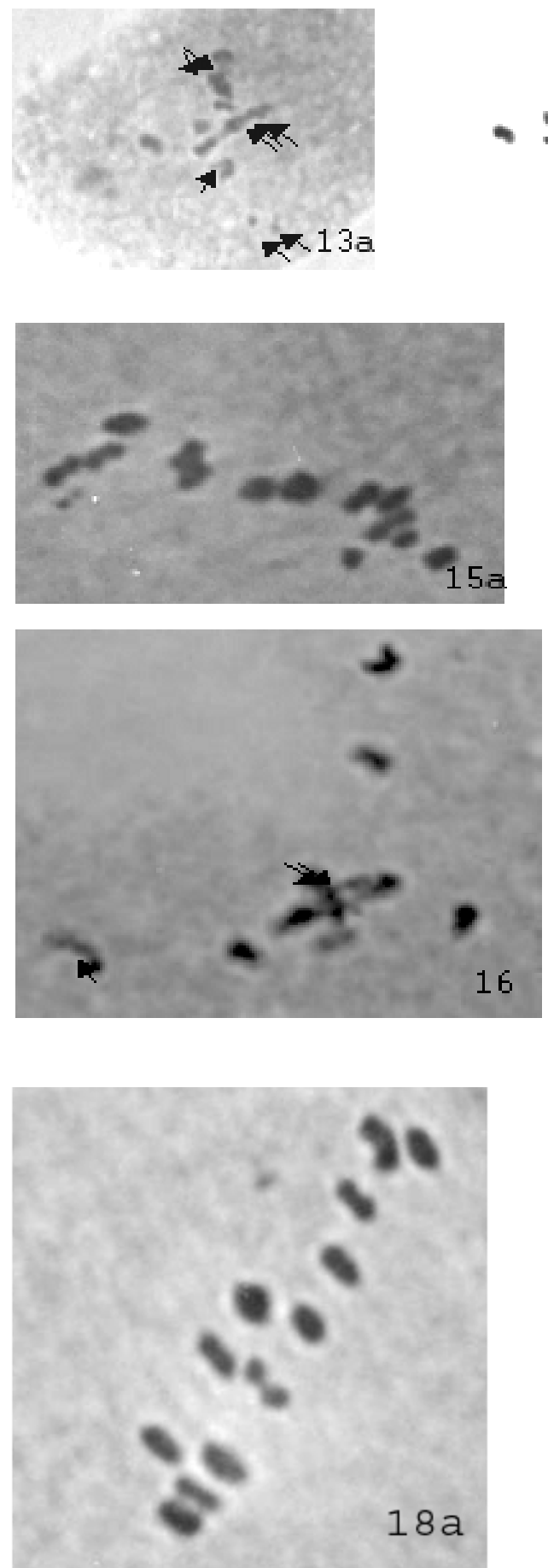
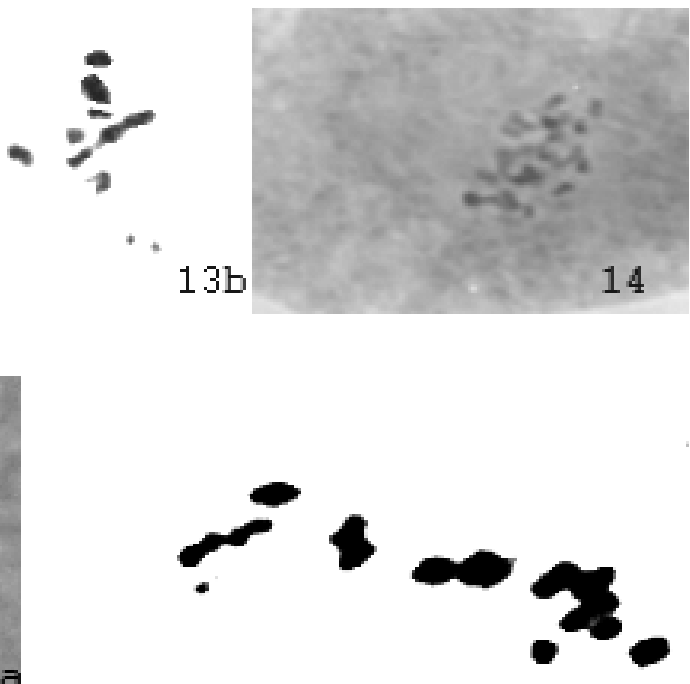

$15 \mathrm{~b}$

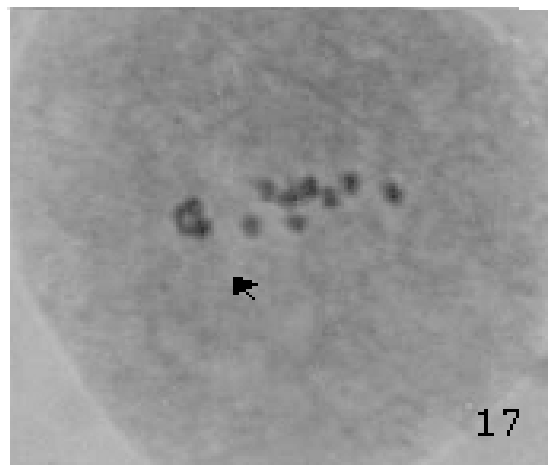

17

Plate 2. Representative photomicrograph of radiation induced cytogenetic aberration at metaphase I. Figure 1-4: Varied degree of sticky chromosomes. Figure 5a,b. Sticky chromosomes with laggards (30KR). Figure 6a,b. Two lagging univalents scattered in the nucleus(30 KR). Figure 7. 2II laggards $(25 \mathrm{KR})$. Figure 8. 10II+1IV(rod type, arrowed) +1 fragment (double arrowed). Figure 9a,b. 8II+1IV(double arrowed) +2 fragments (single arrowed)(30 KR). Figure 10. 7II+1V (arrowed)(35 KR). Figure 11a,b. 1 precocious chromosome or fragments (arrowed) (35 KR). Figure 12a,b. Inability of chromosome to align at equator. Figure 13 a,b. 4II +1 VI (thrice arrowed) $+2 \mathrm{IV}$ (double arrowed) $+2 \mathrm{I}$ (single arrowed) (30 KR). Figure 14. Inability of chromosome to align at equator $(25 \mathrm{KR})$. Figure 15a,b. $12 \mathrm{II}+2$ precocious fragmented chromosomes $(35$ KR). Figure 16. 4 II+1XII(double arrowed)+1IV (arrowed) (35 KR). Figure 17. 9II + 1 VI chromosome ring of $3 \mathrm{II}$ (arrowed) (35 KR) (Figure $\mathrm{b}$ is the retouched micrograph of respective figure a by adjusting the gamma value) 
But cells with laggards were very sporadic not only within the treatment as a whole, but also within the PMC of the same boot. These laggards at the later phase of division might have degenerated or may have resulted in the formation of polyads particularly at the resting phase (Plate 4, Figure 1-5).

\section{Nuclear anomalies in anaphase I}

Aberrant cell observed at this phase was the cell with the bridges with or without fragments, laggards and sticky chromosomes. Among these the most frequent type of aberration within treatment was bridge and the least was the stickiness (Table 3).

The highest aberrant cell was observed at $35 \mathrm{KR}(13.80 \%)$ and the least was observed at $20 \mathrm{KR}(1.53 \%)$ while no aberrant cells were observed at control (Table 3). Like with metaphase and other phases, increasing trend of abnormal cells was observed with the increasing dose of radiation.

\section{Chromatin bridges and fragments at anaphase I cells}

Varying degree of bridges followed by fragments was observed in Anaphase I and II in the irradiated specimen. The fragments observed were of various sizes. And the numbers of bridges observed were also varying in different cells. Bridges, after the multivalent association, scored the highest cause of aberrant cells. It scored as high as $10.35 \%$ of PMC studied at anaphase I in $35 \mathrm{KR}$ treated plants while the least $(1.538 \%)$ was observed with the cells of plants treated with $20 \mathrm{KR}$. As in multivalent association, it represented increasing trend with increasing dose of radiation (Table 2).

Though some bridges lacked the fragments (Plate 3, Figure 5), fragments when present were always associated with the bridges (Plate 3, Figure 1-4). Frequency of fragments in a treatment as a whole was observed to be always lesser than the frequency of bridges observed (Table 2). As with the bridge, fragments were in increasing order with the increasing dose of radiation. The highest count on cells with fragments expressed in term of percentage of the total anaphase cell was noted on $35 \mathrm{KR}(3.448 \%)$. While no fragments were observed at control, 20, 25 and $30 \mathrm{KR}$.

\section{Laggards and sticky chromosomes}

Lagging chromosome occur frequently in anaphase I with or without fragments. It was observed that the number of laggards varies in such abnormal cells (Plate 3, Figure 6-10). The highest number of cells (3.70\%) containing laggards was scored at PMCs' of plants raised from seeds irradiated with $30 \mathrm{KR}$ of gamma ray, while least was observed with $25 \mathrm{KR}(1.493 \%)$ (Table 2). No laggards were observed not only at control but also with $20 \mathrm{KR}$. It thus seems that laggards are induced only at the higher dose of radiation.

Dot like, rod-like fragments including multivalent and bivalents behave as laggards. A bivalent probably with attached fragments seem to tie at the equator (Plate 3, Figure $7 \mathrm{a}, \mathrm{b}$ ). A chain of fragments occurred as a laggard in a few of the PMCs' plants raised from seeds irradiated with higher doses of gamma rays

Similarly, sticky chromosomes was observed at anaphase I. But it had a very low frequency- highest being $1.724 \%$ of the total anaphase I cell at $35 \mathrm{KR}$ (Plate 3). While no stickiness was observed in control, 20 and 25 KR treated plant PMC.

\section{Multinucleated cell in telophase I and interphase cells}

Multinucleated cells (Figure 39, Plate 1-5) were observed in the PMC at radiation treated plants except those treated with $20 \mathrm{KR}$. It had increasing trend with the increasing dose of radiation. This being the highest at $35 \mathrm{KR}(4.16 \%$ / interphase PMC at that treatment) while it was not observed with the control and $20 \mathrm{KR}$ treated plants (Table 2).

\section{DISCUSSIONS}

Studies and comparisons of various physical mutagens and effect on cytogenetics of various plants have already been carried out since as early as 50's in rice (Chang, 1955; Oka et al., 1953; Shastry and Ramiah, 1960; Nair, 1962; Raj et al., 1972; Siddiq, 1973), sorghum (Ramulu, 1971), Vinca rosea (Sudhakaran 1971); Vicia faba (Amer and Mikhael, 1972) and barley (Srivastava, 1974). 

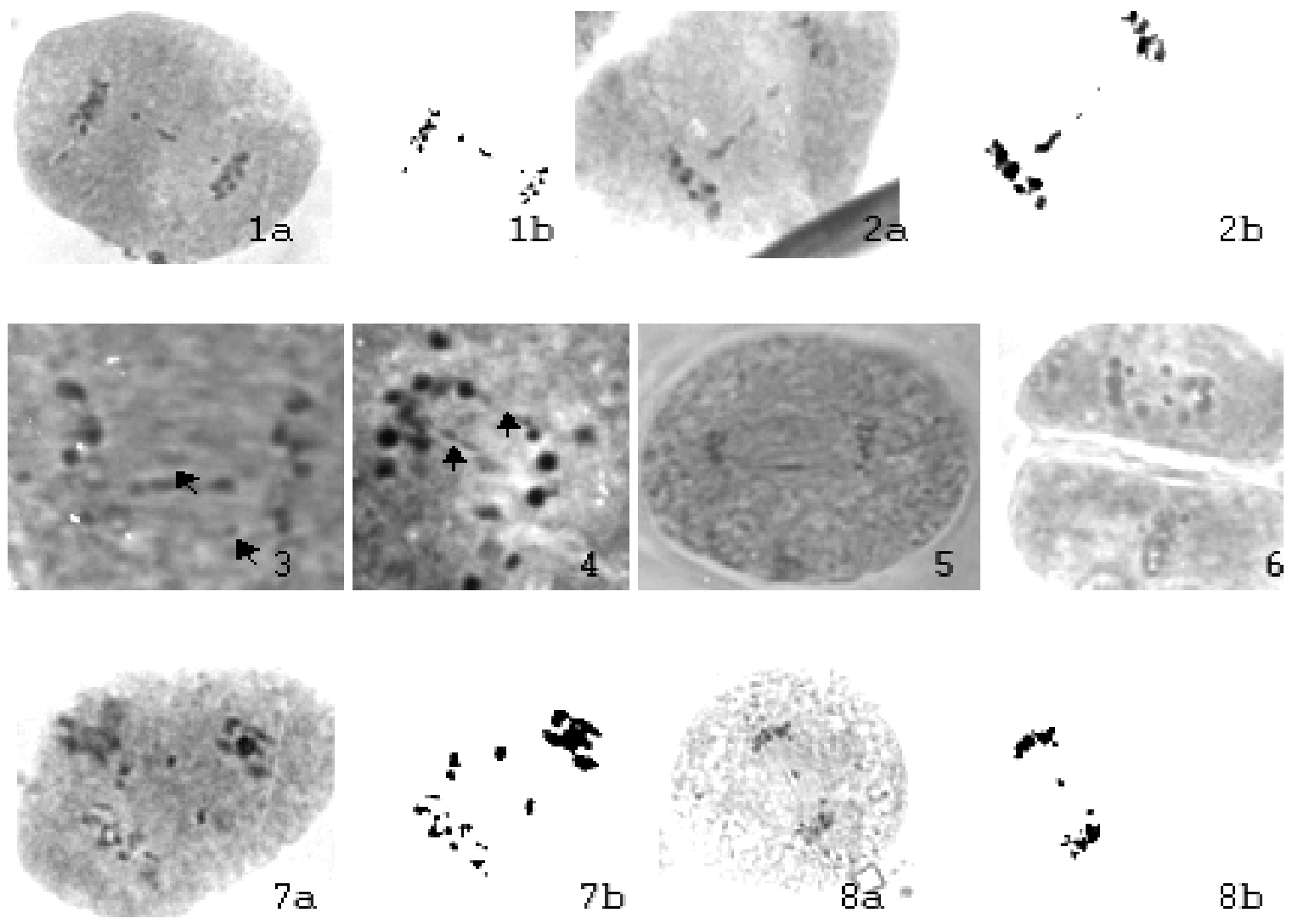

$7 \mathrm{~b}$
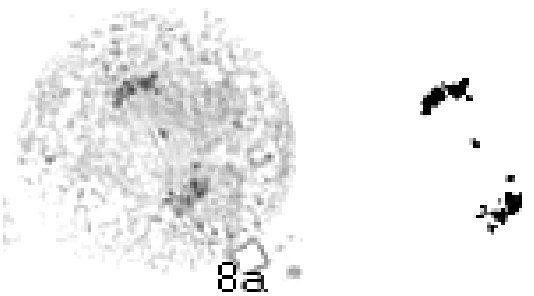

$8 \mathrm{~b}$
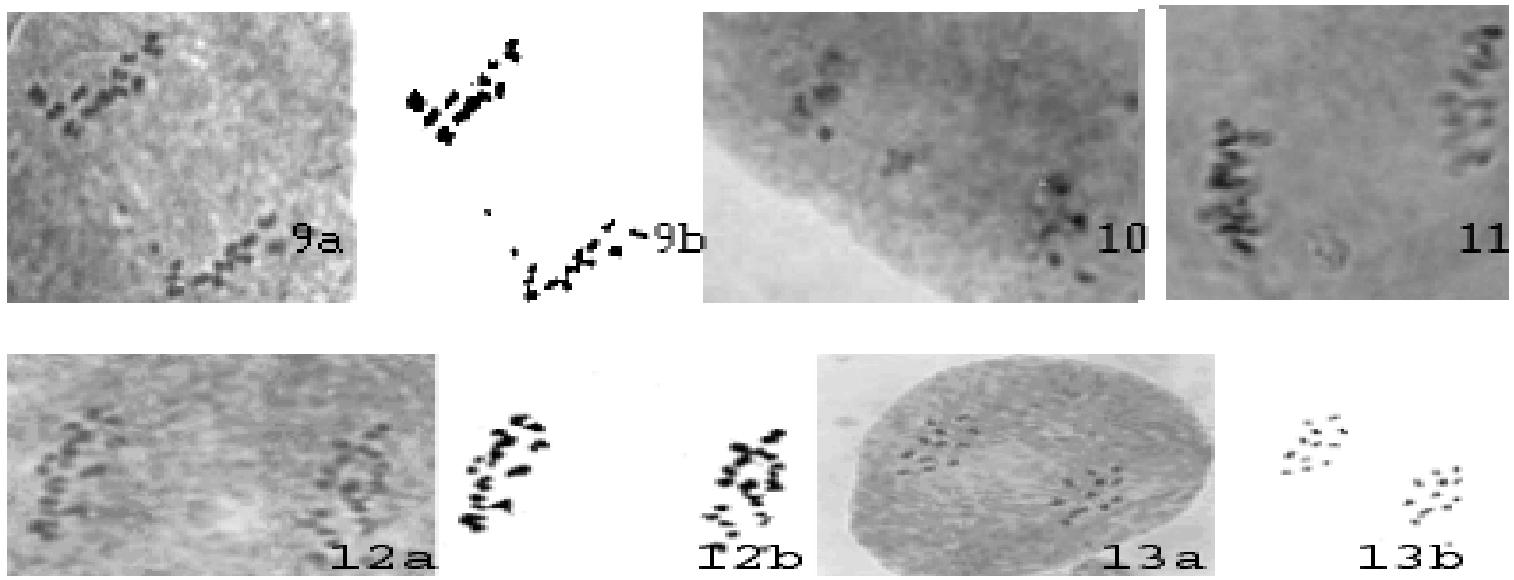

Plate 3. Representative photomicrograph of radiation induced cytogenetic aberration at anaphase I. Figure 1-5. Bridge with/without fragments: 1. Chromatin bridge accompanied by terminalizing two chromatin pieces. 2. Single bridge accompanied by two fragments.3. Single bridge with fragments (arrowed). 4. Two bridge (arrowed). 5. Single bridge without fragments. Figure 6-10. Laggards: 6. Four laggards at AII. 7. Two laggards diffused at the equator, while two other is traveling to the same pole. 8. Two laggards; one pair traveling to pole while other is left behind the equator. 9. Two laggards, in which one lagging sister chromatid is left behind the equator, while the next is traveling to one pole (note: there are 12 chromosome in the upper pole, while $1 \mathrm{I}$ in the lower one ). 10. Fragments/laggards coalesced to form a separate nuclear bodies. Figure 11. Coalesced Sticky chromosomes. Figure 12 a,b. Polyploid cell. Figure 13a,b. Normal anaphase cell at anaphase I with 12-12 chromosomes terminalization

(Figure $b$ is the retouched micrograph of respective figure a by adjusting the gamma value) 

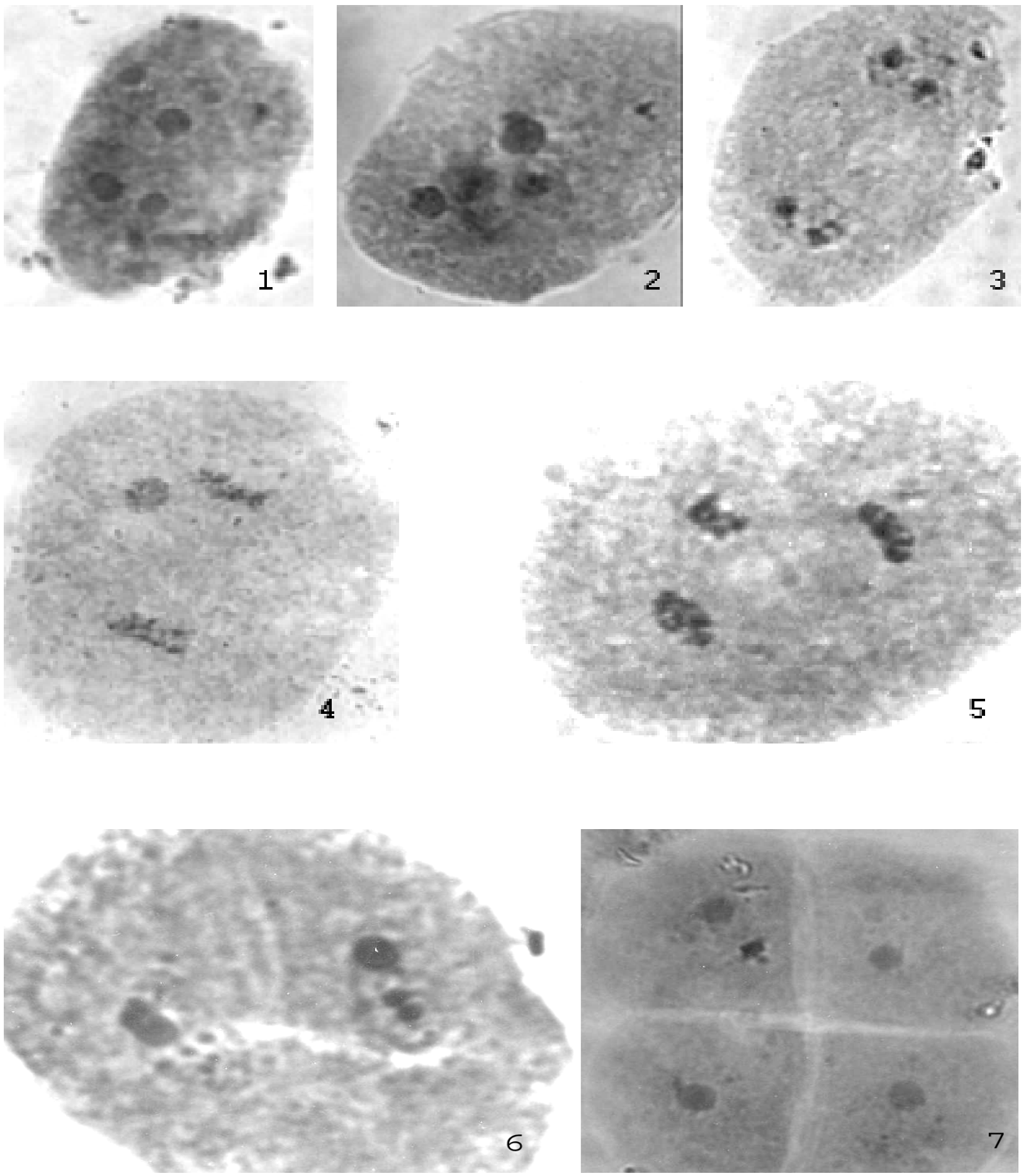

Plate 4. Representative photomicrograph of radiation induced cytogenetic aberration at telophase I and interphase cells. Figure1-6. Different types of abnormal PMCs' at telophase and interphase stages observed in plants raised with irradiated seeds.1. A cell having five nuclei with distinct five nucleoli of varied sizes observed at interphase PMCs' of irradiated population (35 KR). 2. An interphase cell having four distinct nuclei observed in a plant raised with $30 \mathrm{KR}$ treated seeds. 3. Interrupted cytokinesis resulting four nucleated cells, having distinct nucleoli with some micro nucleoli observed in PMC of the $25 \mathrm{KR}$ treated plant. 4. Micronuclei in the telophase cells observed in PMC of the plant raised from 35 KR treated seeds. 5. Telophase PMC having tripolar orientation of chromosomes presumably formed by laggards observed at 35 KR. 6. Micro nucleated cell observed at 35 KR. Figure 7. Normal tetrad cell. 
Cytological and genetic effects of radiation of $\mathrm{Co}^{60}$ are mostly as a result of chromosomal aberrations at microscopic and submicroscopic levels (Raj et al., 1972). Comparable effect of radiation was observed in the current research too. Significant effect of radiation on inducing aberration was observed for the entire radiation spectrum. Different types of aberration observed were the asynaptic / desynaptic behavior of chromosomes, multivalent association of chromosomes, chromatin bridges, laggards, fragments, multinucleated cells, stickiness etc. Multivalents were the most frequent abnormality noted in the $\mathrm{M}_{1}$ generation, the highest association observed being a XII, and the radiation treatment at $35 \mathrm{KR}$ induced the highest score $(17.94 \%)$ of cells having multivalent association compared to other dose spectrum. Multivalent association as a cause of reciprocal translocation in irradiated material was reported in rice by various researchers (Oka et al., 1953; Caldecott et al., 1954; Chang, 1955; Nair, 1962; Raj, et al., 1972; Siddiq, 1973).As per the report of Gaul (1964) the cases of two translocation per cell of ring and chain form of 5 and 6 chromosomes were observed in number of cases in 30 and $35 \mathrm{KR}$ treated plants (Plate 1, Figure2, 6, 9,16). Various interpretations were forwarded to account the breakage of chromosomes by ionizing radiations (Sax, 1941 c.f. Sudhakaran, 1971). But all the result has the same focal point that the radiation can induce chromosome breakage at the microscopic and submicroscopic level not only by the direct hits but also indirectly by the reactive chemical products produced in water surrounding the chromosomes. It is quite likely that in the current research the effect of ionizing radiation has indirectly induced an imbalance in the physiology of cell probably through the production of a chemical substance unknown to the metabolic machinery of the cell. This is well presented by the occurrence of clumping and stickiness of chromosomes at the early stages of meiosis that may all indicate the disturbances in the synthesis of DNA in the PMC. This breakage and consequent reunion of the broken ends thus resulted multivalent configuration.

Partial asynaptic and desynaptic behavior of chromosomes were observed in the radiation treated PMC. Thirty-five KR treated plants scored the highest frequency $(0.65 \%)$ of this phenomenon. The presence of univalent is may be due to the partial asynaptic or desynaptic behavior of the gene mutation, chromosomal breakage and environmental condition (Riley and Law, 1965). There are reports explaining expression of such desynaptic behavior of chromosomes on the certain temperature regime (Chao and Hu, 1961; Srivastava, 1974).

Formation of bridges was reported earlier, following radiation treatment in the rice plant (Shastry and Ramiah, 1961; Siddiq, 1973). Chromosomal bridges accompanied by fragments were less frequent than multivalent in all the treatments studied. The highest score for bridged cells were observed at 35 KR (10.345 \%). Siddiq (1973) also reported positive relation of bridge formation with radiation. Thus it is evident that the radiation induces the breakage and fusion of chromosome, and the extent increases with the increasing dose of radiation. With some speculation, the reason for having these bridges may be due to inversion primarily paracentric. Though formation of bridge and acentric fragments don't always indicate occurrence of paracentric inversion as these can be brought about by spontaneous breakage and fusion of chromosomes during meiosis (Haga, 1953). The formation of bridge at anaphase II can be due to due to four strand double crossover combined with two strand single cross over in the region between the centromere and the inversion loop, which results bridges in each of the two AII.

It was observed that lagging chromosomes fail to reach the pole before the chromosomes relax to uncoil to form daughter nuclei and the either disintegrate or form micronuclei (Plate 4, Figure 5). Thus the nondisjunction of the chromosome relaxes to uncoil to form daughter nuclei and then either disintegrate or form micronuclei. Several authors have reported varying degree of laggards in the PMC of the plant treated with radiation in crops Lens culinaris (Sinha and Godward, 1969) Trigonella foenum graecum (Sudhakaran, 1971; Raghuvanshi and Singh, 1974), Vicia faba (Amer and Mikhael, 1972) and in rice (Siddiq, 1973). The highest score of lagging chromosomes at metaphase I and anaphase I was observed at $35 \mathrm{KR}(4.67 \%)$ and $30 \mathrm{KR}(3.7 \%)$ respectively.

Very small percentage of cells showed the fragment in the diakinesis and metaphase cells (Plate 2, Figure $8,9,11,15)$, the highest $\%$ of cells having fragments were observed at $25 \mathrm{KR}(1.53 \%)$, while no fragments were observed with $20 \mathrm{KR}$ and very less at $30 \mathrm{KR}(0.79 \%)$ (Table 2). The reason for this reduction in cell containing fragment may be the degeneration of the fragments in the nucleus soon after entering into the metaphase stage.

Similarly sticky chromosomes as a result of aggregation of chromosomes were observed at metaphase I (Plate 2, Figure 1-5). Though with very less frequency, the highest percent of PMC having sticky chromosomes was observed at $35 \mathrm{KR}(1.34 \%)$ and the least at $30 \mathrm{KR}(0.79 \%)$ (Table 3). It is observed that the stickiness was the least affected aberration induced by the radiation. Similar granules as a result of stickiness were observed in rice PMC treated by gamma ray (Siddiq, 1973; Sudhakaran, 1971) and chemicals (Sparrow and Hammond, 1947). 
Finally, it could safely be concluded that, the greater the radiation dose, greater is its effect in the nuclear material of rice PMC. And harnessing such useful translocation and inversion stocks, new vistas for genetic and breeding studies could be ventured.

\section{ACKNOWLEDGEMENTS}

Immense appreciation is towards the B.P. Memorial Cancer Hospital, Chitwan for allowing the irradiation of the seeds. The present work was partially supported by the grant of DOR, Institute of Agriculture and Animal Sciences, Chitwan, Nepal.

\section{REFERENCES CITED}

Amer, S. M. and E. Mikheal. 1972. Cytogenetic studies on the effect of $\mathrm{Co}^{60}$ r-irradiation on Vicia faba. Cytologia. 37: 169-174.

Caldecott, R. S., B. H. Beard and C. O. Gardner. 1954. Cytogenetic effects of X-ray and thermal neutron irradiation on seeds of barley. Genetics. 39: 240-259.

Chang, W. T. 1955. Reciprocal translocation in rice by X-ray. Jap. J. Breed. 5: 27-31.

Chao, C. Y. and W. L. Hu. 1961. The effect of temperature on a desynaptic gene in rice. Bot. Bull. of Acad. Sinica. 2: 87-100.

Evans, D. A. amd S. M. Reed. 1981. Cytogenetic techniques. In: T. A. Thope (ed.) Plant Tissue Culture: Methods and Application in Agriculture. Academic Press Inc. pp. 224.

Gaul, H. 1964. Mutations in plant breeding. Rad. Bot. 4: 155-232.

Haga, T. 1953. Meiosis in Paris II. Spontaneous breakage and fusion of chromosomes. Cytologia. 18: 50-66.

Khan, S. H. 1975. A technique for staining rice chromosomes. Cytologia 40: 595-598.

Nair, N. M. 1962. Cytological studies of gamma irradiated rice varieties. Cytologia. 37: 352-365.

Oka, H. I., J. Hayashi and I. Shiojiri. 1958. Induced mutations of polygenes for quantitative characters in rice. J. Heredity. 49: 11-14.

Oka, H. I., T. T. Chang and M. S. Hong. 1953. Reciprocal translocation in rice (A preliminary note). Japan J. Genet. 32: 20-27.

Pokhrel, T. P. 1997. An overview of newly released rice varieties in Nepal. Nep. Agri. Re. Jornal. 1: 100-102.

Raghuvanshi, S. S. and A. K. Singh. 1974. Studies on the effect of gamma ray on Trigonella foenum-graecum L. Cytologia. 39: 473-482.

Raj, A.Y., A. S. Raj and G. Madhusudana Rao. 1972. Mutagenic studies of gamma rays on Oryza sativa L. Cytologia. 37: 469-477.

Ramulu, K. S. 1971. Induced structural changes and meiotic aberrations in sorghum. Cytologia. 36: 229-236.

Riley, R. and C. N. Law. 1965. Genetic variation in chromosome pairing. Adv. Genet. 13: 57-114.

Sax, K. 1941. Types and frequencies of chromosomal aberration induced by X-rays. Cold. Spr. Harb. Sympo. Quant. Biol. 9: 93-101.

Sears, E. R. 1956. The transfer of leaf-rust resistance from Aegilops umbellulata to wheat. Wheat genetics in plant breeding. Brookhaven Symp. Biol. 9: 1-22.

Shastry, S. V. S. and K. Ramiah. 1960. Cytogenetical effects of x-rays, thermal neutrons and beta-particles on Oryza sativa L. Indian J. Genet. 21 (1): 43-50.

Siddiq, E. A. 1985. Mutation research and crop improvement. Rice Research in India. pp. 110-144.

Siddiq, E. A. 1973. Cytogenetical effects of physical and chemical mutagens in rice. Indian J. Genet. 33 (2): 163-170.

Sinha, S. S. N. and M. B. E. Godward. 1969. Radiation studies in Lens culinaris: Distribution of Chiasmata between nuclei and within nuclei in irradiated and non-irradiated populations. Cytologia. 34: 45-51.

Sparrow, A. N. and M. R. Hammond, 1947. Cytological evidence for the transfer of DNA from nucleus to cytoplasm in certain plant cells. American J. Bot. 34: 439-445.

Srivastava, M. 1974. Radiation induced desynaptic mutant in barley. Cytologia. 39: 63-68.

Sudhakaran, I. V. 1971. Meiotic abnormalities induced by gamma rays in Vinca rosea Linn. Cytologia. 36: 67-79.

Upadhyaya, H. K. 1995. Rice research in Nepal: Current state and future priorities. In: R. E. Evenson, R. W. Herdit and M. Hossain (eds.) Rice Research in Asia: Progress and Priorities. CAB International. pp. 193-215. 